\section{Endocarditis infecciosa de la válvula tricúspide en paciente no adicto a fármacos y sin cardiopatía previa predisponente}

\section{Tricuspid valve endocarditis in a non-drug-addicted patient with no prior predisposing cardiopathy}

\section{Introducción}

La endocarditis infecciosa (EI) es una enfermedad mortal. A pesar de las mejoras en su manejo, la El sigue estando asociada a gran mortalidad y complicaciones graves ${ }^{1}$. La El que afecta a cavidades derechas es más infrecuente, reportándose entre un 5-10\% del total de casos, usualmente estos casos están asociados al uso intravenoso de fármacos, infecciones de dispositivos cardíacos, catéteres venosos centrales, virus de inmunodeficiencia humana (VIH) y cardiopatías congénitas ${ }^{2}$.

\section{Presentación del caso}

Paciente masculino de 28 años de edad, con antecedentes de asma bronquial. Alrededor de 4 meses antes de ser admitido en el servicio de cardiología comenzó con dolor en la región del calcáneo del miembro inferior derecho, que fue interpretado como fascitis plantar derecha por la especialidad de ortopedia, prescribiéndose en ese momento rehabilitación y fisioterapia del miembro. Posteriormente, reapareció el dolor en la región dorsal del miembro inferior derecho, en ese momento acompañado de aumento de volumen, motivo por el cual fue remitido a la especialidad de reumatología, donde, luego de valorar el caso, se diagnostica una espondilitis anquilopoyética, iniciando tratamiento con prednisona $40 \mathrm{mg}$ diarios y salazosulfapiridina. A la cuarta semana del tratamiento comenzó la aparición de enrojecimiento en el tronco y los miembros superiores, acompañado de fiebre de 39 a $40^{\circ} \mathrm{C}$, diarrea, toma del estado general, adenopatías cervicales bilaterales de aspecto inflamatorio y disfagia con enrojecimiento de la faringe y exudados en ambas amígdalas; se interpretó el cuadro como una faringoamigdalitis exudativa y se inició tratamiento con penicilina cristalina, a la cual reaccionó con la aparición de una erupción de tipo exantema. Se decidió cambiar el tratamiento a ceftriaxona y realizar pruebas por la sospecha de una mononucleosis infecciosa; como resultado se obtuvo una proteína $C$ reactiva (PCR) positiva a virus herpes simple tipo 6, lo que motivó el inicio de tratamiento con ganciclovir. Transcurridos los primeros días de tratamiento se constataron lesiones cutáneas puntiformes rojizas en ambas piernas y el tronco. Luego de varias semanas de tratamiento, se detectó durante un examen físico de rutina un soplo cardíaco, de mayor intensidad en borde esternal izquierdo hacia la punta, por lo que fue derivado a nuestro servicio.

Antecedentes patológicos personales: asma bronquial desde los 2 años de edad, sin tratamiento. Espondilitis anquilopoyética. Antecedentes patológicos familiares de hipertensión arterial y cardiopatía isquémica. Operaciones: hernia inguinal izquierda a la edad de 24 años. No antece-

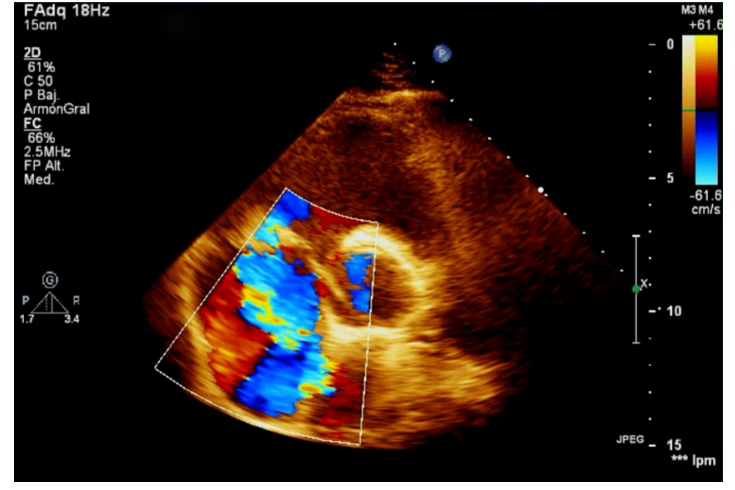

Figura 2 Ecocardiograma transtorácico. Plano paraesternal, eje corto o transversal a nivel de los grandes vasos. Doppler color que muestra jet de regurgitación tricuspídea severa por déficit en la coaptación valvular tricuspídea.

dentes de traumatimos o transfusiones. Se reportó reacción alérgica a la penicilina y no se recogieron reportes de hábitos tóxicos ni drogodependientes.

En el examen físico se detectaron los siguientes datos positivos: peso: $83 \mathrm{~kg}$, talla: $1,76 \mathrm{~m}$ y un índice de masa corporal de $26.79 \mathrm{~kg} / \mathrm{m}^{2}$. Temperatura axilar de $39.2^{\circ} \mathrm{C}$. En la región del cuello se observó una distensión venosa yugular con una onda sistólica prominente. En el sistema cardiovascular se ausculta un soplo sistólico II/vı de mayor intensidad en el $4 .^{\circ}$ espacio intercostal paraesternal izquierdo y la región subxifoidea, con un aumento de intensidad durante la inspiración, una presión arterial de $110 / 80 \mathrm{mmHg}$ y una frecuencia cardíaca de 97 latidos por minuto. En el abdomen se advirtió la presencia de una hepatomegalia de alrededor $1 \mathrm{~cm}$ por debajo del reborde costal, de consistencia firme, no dolorosa. Tejido celular subcutáneo infiltrado en ambos miembros inferiores hasta $1 / 3$ inferior tibial de fácil godet.

Como parte de los análisis de laboratorio realizados, se reportó una leucocitosis ligera con desviación a la izquierda. Velocidad de eritrosedimentación de $96 \mathrm{~mm} / \mathrm{h}$. PCR, positiva. Factor reumatoideo, positivo. Serología VIH, negativa.

Se realizó un ecocardiograma transtorácico (ETT) (figs. 1 y 2), donde se apreció una imagen ecogénica en la valva anterior de la tricúspide, compatible con vegetación mayor de $17 \times 21 \mathrm{~mm}$ que generaba déficit en la coaptación valvular con insuficiencia de la misma, además de una disfunción sistólica del ventrículo derecho con un TAPSE de $8 \mathrm{~mm}$ y un ventrículo derecho de $41 \mathrm{~mm}$ en su base, con desplazamiento del tabique interventricular hacia la izquierda. Aurícula derecha dilatada, con desplazamiento del septum interauricular hacia la izquierda. Flujo pulmonar con un tiempo de aceleración de $95 \mathrm{~ms}$ y una presión media de la arteria pulmonar de $32 \mathrm{mmHg}$. Se confirmaron hallazgos a través de ecocardiograma transesofágico (ETE), realizado sin complicaciones.

Se realizaron 4 hemocultivos donde se aislaron la bacteria gramnegativa Acinetobacter calcoaceticus (A. calcoaceticus) y Staphylococcus aureus (S. aureus); S. aureus sensible a vancomicina y resistente a oxacilina; Acinetobacter calcoaceticus sensible a astreonam, moxifloxacino y meropenem.

Se diagnosticó una El de válvula tricúspide de origen polimicrobiano en paciente con compromiso inmunológico secundario a enfermedad reumática de base y al tratamiento seguido para la misma; se inició tratamiento antibiótico 


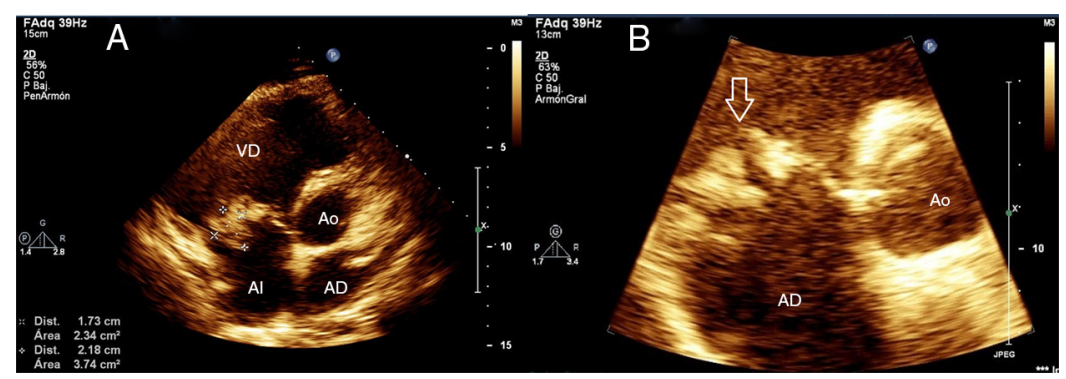

Figura 1 Ecocardiograma transtorácico. Plano paraesternal eje corto o transversal a nivel de los grandes vasos. A) Aurícula derecha (AD), aurícula izquierda (Al), ventrículo derecho (VD), válvula aórtica (Ao), imagen ecogénica en la valva anterior de la tricúspide, compatible con vegetación mayor de $17 \times 21 \mathrm{~mm}$ ). B) Ampliación del aparato valvular tricúspide donde se observan imágenes ecogénicas en ambas valvas, siendo la mayor la observada en valva anterior.

parenteral guiado por hemocultivos y antibiogramas con las respectivas concentraciones mínimas inhibitorias, el cual se mantuvo por 4 semanas, manteniendo estabilidad clínica y hemodinámica. Al término de las 4 semanas, persistía vegetación de $20 \mathrm{~mm}$ acompañada de disfunción del ventrículo derecho secundaria a insuficiencia tricúspide, por lo que se decidió el reemplazo valvular tricúspide por prótesis biológica, proceder que transcurrió sin complicaciones. La vegetación de la válvula tricúspide se envió a estudio histopatológico, reportando restos de fibrina y zonas trombosadas, signos de inflamación aguda y zonas organizadas de tejido fibrótico compatibles con una vegetación. No se aislaron microorganismos en el estudio microbiológico.

La El derecha es casi infrecuente en pacientes con estados de inmunodeficiencias no asociadas a VIH y de pacientes inmunocompetentes $^{1,2}$. S. aureus es el microorganismo predominante (60-90\% de los casos); sin embargo, la frecuencia de actividad polimicrobiana es cada vez más frecuente ${ }^{3}$. La El asociada a bacilos gramnegativos es infrecuente y en la mayoría de los casos está presente en las infecciones asociadas a servicios hospitalarios o a El de válvulas protésicas; de este grupo, la Pseudomona aeruginosa (P. aeruginosa) es la bacteria más frecuente ${ }^{4,5}$. A. calcoaceticus u otras especies han sido de escaso reporte en la literatura médica asociado a las El de cavidades derecha; en su mayoría, estas bacterias comparten las mismas características epidemiológicas que su grupo ${ }^{6}$; las mismas han sido reportadas responsables de El no asociada a servicios hospitalarios ${ }^{7}$.

Las manifestaciones más comunes de la El derecha son fiebre persistente, bacteriemia y múltiples émbolos sépticos pulmonares, que pueden manifestarse en forma de dolor torácico, tos o hemoptisis. Cuando se producen émbolos sistémicos, se debe considerar una posible embolia paradójica o El izquierda asociada ${ }^{8,9}$. La ETT suele permitir la evaluación de la enfermedad tricuspídea debido a su localización anterior y las frecuentes vegetaciones grandes. Se deben evaluar siempre las válvulas de Eustaquio y valvas pulmonares. La ETE es más sensible para la detección de vegetaciones pulmonares y afección izquierda asociada ${ }^{1}$.

La presencia de insuficiencia cardíaca (IC) derecha secundaria a insuficiencia tricuspídea grave, con mala respuesta al tratamiento diurético, la El causada por microorganismos difíciles de eliminar (p. ej., hongos persistentes) o bacteriemia de al menos 7 días (S. aureus, P. aeruginosa) a pesar de una terapia antimicrobiana adecuada o la presencia de vegetaciones $>20 \mathrm{~mm}$ en la válvula tricúspide persistentes y asociado a émbolos pulmonares recurrentes, con o sin IC derecha concomitante anuncian la necesidad de una intervención quirúrgica. La sustitución de la válvula tricúspide es la estrategia más frecuente, habitualmente con implante de válvula bioprotésica, conducta seguida en el caso presentado ${ }^{10,11}$.

\section{Conclusiones}

La endocarditis derecha de la válvula tricúspide es poco frecuente, en especial cuando no existen factores de riesgo para su aparición. Su diagnóstico temprano y oportuno es imprescindible para óptimo tratamiento. Los criterios quirúrgicos de abordaje de esta entidad deben considerarse en estos pacientes siguiendo los criterios establecidos.

\section{Bibliografía}

1. Guía ESC 2015 sobre el tratamiento de la endocarditis infecciosa. Rev Esp Cardiol. 2016;69:69.

2. Cahill T, Prendergast B. Infective endocarditis. Lancet. 2016;387:12 [Internet] [consultado 9 Sep 2017]. Disponible en: https://doi.org/10.1016/S0140-6736(15)00067-7

3. Sousa C, Botelho C, Rodrigues D, et al. Infective endocarditis in intravenous drug abusers: An update. Eur J Clin Microbiol Infect Dis. 2012;31:2905-10.

4. Heydari AA, Safari H, Sarvghad MR. Isolated tricuspid valve endocarditis. Int J Infect Dis. 2009;13:e109-11.

5. Yuan S-M. Right-sided infective endocarditis: Recent epidemiologic changes. IJCEM. 2014;7:199-218 [Internet] [consultado 9 Sept 2017]. Disponible en: http://www.ncbi.nlm.nih.gov/ pmc/articles/PMC3902260/

6. Chen Q, Cao H, Lu H<ET_AL>. Bioprosthetic tricuspid valve endocarditis caused by Acinetobacter baumannii complex, a case report and brief review of the literature. J Cardiothorac Surg. 2015;10:149 [Internet] [consultado 9 Sept 2017]. Disponible en: http://www.ncbi.nlm.nih.gov/ pmc/articles/PMC4634728/

7. Gradon JD, Chapnick EK, Lutwick LI. Infective endocarditis of a native valve due to Acinetobacter: Case report and review. Clin Infect Dis. 1992;14:1145-8.

8. Chahoud J, Sharif Yakan A, Saad H, et al. Right-sided infective endocarditis and pulmonary infiltrates: An update. Cardiol Rev. 2016;24:230-7 [Internet] [consultado 9 Sept 2017]. Disponible en: https: / / www.scopus.com/inward/record.uri?eid=2-s2.084945300435\&doi=10.1097\%2fCRD 0000000000000095\&partne $\mathrm{rID}=40 \& \mathrm{md} 5=4 \mathrm{~b} 9 \mathrm{~b} 0 f 871 \mathrm{e} 71 \mathrm{e} 44 \mathrm{caaea} 5 \mathrm{f} 987870507 \mathrm{e}$ 
9. Hussain ST, Shrestha NK, Witten J, et al. Rarity of invasiveness in right-sided infective endocarditis. J Thorac Cardiovasc Surg [Internet]. 2017 [consultado 10 Sept 2017]. Disponible en: https: / / www. scopus.com/inward/record. uri?eid=2-s2.0$85029757872 \&$ doi $=10.1016 \% 2 \mathrm{fj} . j \mathrm{jtcvs} .2017 .07 .068 \&$ partner $I D=$ 40\&md5=30ef6dd74dd3edc39ce6901516520456

10. Utsunomiya H, Berdejo J, Kobayashi S, et al. Evaluation of vegetation size and its relationship with septic pulmonary embolism in tricuspid valve infective endocarditis: A real time 3DTEE study. Echocardiography. 2017;34:549-56.

11. Singer $M$, Alkady $H$, Mohsen $T$, et al. Predictors of surgical outcome in isolated tricuspid valve endocarditis: Single center experience of 60 patients. Thorac Cardiovasc Surg [Internet]. 2017 [consultado 7 Oct 2017]. Disponible en: https://www. scopus.com/inward $/$ record. uri?eid=2-s2.0-85029695162\&doi= $10.1055 \% 2 \mathrm{fs}-0037-1606386 \&$ partner ID $=40 \& \mathrm{md} 5=\mathrm{e} 74 \mathrm{fdb} 0 \mathrm{c} 12$ f2de3ede7ce332309e7cab
Adrian Naranjo*, Daniela Ruiz

y Aylen Pérez

\section{Cardiocentro, Centro de Investigaciones Médico Quirúrgico, La Habana, Cuba}

* Autor para correspondencia. Calle 33. ${ }^{a} \mathrm{~N} .{ }^{\circ} 6216$ entre 62 y 64. Municipio Playa. Cuba. Tel.: +53 53101674.

Correo electrónico: anaranjod90@gmail.com (A. Naranjo).

https://doi.org/10.1016/j.acmx.2018.02.006

1405-9940/

(c) 2018 Instituto Nacional de Cardiología Ignacio Chávez. Publicado por Masson Doyma México S.A. Este es un artículo Open Access bajo la licencia CC BY-NC-ND (http:/ / creativecommons.org/ licenses/by-nc-nd/4.0/).

\section{Resolución a corto plazo de las líneas B en la ecografía torácica con edema agudo de pulmón tras tratamiento}

\section{Short-term resolution of B-lines in thoracic ultrasound in acute pulmonary oedema after treatment}

\section{Introducción}

La ecografía torácica (ET) ha demostrado ser una nueva herramienta para los médicos de los servicios de urgencias al evaluar a los pacientes que se presentan con disnea aguda. La misma se ha descrito recientemente como una herramienta útil para estimar el grado de congestión pulmonar y monitorizar la efectividad del tratamiento ${ }^{1}$, específicamente la presencia de sonográfica de las líneas B se asocia con estados de sobrecarga de líquidos. Ha demostrado ser particularmente útil al diferenciar entre la enfermedad pulmonar obstructiva crónica (EPOC) y la insuficiencia cardiaca congestiva $(\mathrm{IcC})^{2-4}$. Las líneas $\mathrm{B}$ aisladas pueden verse en los pulmones normales, pero las líneas B difusas en múltiples zonas indican edema intersticial, siendo más habitual en el edema agudo de pulmón ${ }^{3}$. La ET podría utilizarse no solo para para diagnosticar el edema pulmonar, sino también para el seguimiento y la efectividad del tratamiento.

A pesar de estos hallazgos la ET no se utiliza de manera rutinaria para evaluar la evolución o la respuesta al tratamiento en pacientes con edema agudo pulmonar en el contexto de la ICC. Presentamos el caso clínico de una paciente con edema agudo de pulmón que tras tratamiento médico, a las $2 \mathrm{~h}$ y media presenta una resolución a muy corto plazo de las líneas B en la ET.

\section{Presentación del caso}

Paciente mujer de 72 años con antecedentes personales de fibrilación auricular, ICC y EPOC moderada que acude al servicio de urgencias por presentar disnea de $2 \mathrm{~h}$ de evolución.
A la llegada del servicio de urgencias prehospitalarias, la paciente refiere un aumento de su disnea habitual en las últimas $48 \mathrm{~h}$ acompañada de tos no productiva con empeoramiento de los síntomas en las últimas $2 \mathrm{~h}$. Paciente obesa que al examen físico presentaba una frecuencia respiratoria (FR) de 56 rpm, presión arterial de 190/110, frecuencia cardiaca de $150 \mathrm{lpm}$ y saturación de oxígeno del $66 \%$ con uso de la musculatura accesoria. Ruidos cardiacos arrítmicos y sibilancias bilaterales con edemas maleolares bilaterales. Se inició tratamiento con oxigenoterapia de alto flujo con reservorio, aerosolterapia con bromuro de ipratropio $0,5 \mathrm{mg}$ y salbutamol $5 \mathrm{mg}$, furosemida $40 \mathrm{mg}$ intravenoso y nitroglicerina sublingual.

A su llegada a urgencias, aproximadamente $3 \mathrm{~h}$ después de que comenzaron los síntomas clínicos, la paciente continuaba con disnea en reposo con evidente uso de musculatura accesoria y FR de $44 \mathrm{rpm}$. El electrocardiograma mostró fibrilación auricular con respuesta ventricular rápida, sin cambios isquémicos. El diagnóstico diferencial inicial fue reagudización de EPOC vs. edema agudo del pulmón (cardiogénico). Se realizó una ecografía a la cabecera del paciente o point-of-care ultrasound (POCUS), utilizando el protocolo RADiUS ${ }^{5}$ para disnea. La ET mostró líneas B bilaterales de $3 \mathrm{~mm}$ o menos de separación en los 8 sitios explorados utilizando el enfoque de Volpicelli et al. ${ }^{3}$ sugestivas de edema agudo del pulmón (cardiogénico) (fig. 1) asociado a derrame pericárdico y derrame pleural derecho, además mostró una fracción de eyección reducida subjetiva de aproximadamente el $25 \%$ con distensión de la vena cava inferior. La radiografía de tórax mostró signos compatibles con edema agudo de pulmón. Se inició protocolo de ventilación mecánica no invasiva con CPAP y se añadieron $60 \mathrm{mg}$ de furosemida vía intravenosa, así como perfusión IV de nitroglicerina. Se realizó sondaje vesical obteniéndose una diuresis de $1.500 \mathrm{cc}$. Dos horas y media después del inicio del tratamiento, el estado respiratorio de al paciente había mejorado. Se realizó una ET repetida (fig. 2) que mostró una resolución completa de las líneas $B$ en los 8 sitos explorados de la pared torácica. La paciente estaba alerta, se retiró la CPAP, fue capaz de hablar en frases completas y presentó una evidente mejora de su estado general. La paciente fue ingresada en el servicio de medicina interna y dada de alta $72 \mathrm{~h}$ después. 